\title{
Research and Implementation of Wisdom Campus System Based on Android Platform
}

\author{
Yanqiu Wang ${ }^{1, a}$ and Xiaofei Yan ${ }^{1, b^{*}}$ \\ ${ }^{1}$ College of Information Science and Engineering, Zaozhuang University, China \\ aww_yanqiu@163.com, byanxf_sytu@163.com
}

Keywords: Android platform; Internet service; Mobile smart campus; System design

\begin{abstract}
With the rapid development of internet, cloud computing and mobile application development, smart campus system is paid more attention by more and more scholars. In China, many scholars have already explored the concept of smart campus. Against this background, we carry out research on the development and implementation of mobile smart campus.
\end{abstract}

\section{Introduction}

In recent years, with the popularization of the domestic $4 \mathrm{G}$ network and the rapid development of mobile internet technology, the number of smart mobile terminals has grown rapidly. The application based on the android platform has the features of instant convenience, quick and easy use, intelligent and safe performance Rapid development. The traditional campus management model is single, inefficient and poorly coordinated. In this context, mobile smart campus system came into being. "Mobile smart campus" refers to a smart campus that uses mobile terminals as a point of departure and systematic services. The smart campus provides an integrated environment of management, learning and living. This integrated environment is based on various application service systems and fully integrates the teaching, research, management and campus life of schools to create a smart campus, wisdom service and wisdom management As one of the new campus application platform.

Wisdom Campus "is an inevitable result under the big data of the campus. Its wisdom is reflected in a smart learning environment, intelligent student management, and smart lifestyle. It is reflected in the automatic monitoring of school safety; intelligent attendance and attendance system; In short, is to develop an intelligent campus operation, maintenance and management collaboration system, effectively enabling the campus can be intelligent, environmentally friendly, stable and safe operation, and sharing of campus big data, To achieve a more reasonable, accurate and comprehensive campus management system only to improve the management efficiency of all levels of the campus and reduce the economic costs of campus management. BIM application technology as a carrier to build an overall data sharing platform that can carry out three-dimensional space Data visualization query, application, and fully integrated in the organic management of campus building and structural system of information and data to achieve rapid query, co-ordinate management, reduce campus management difficulties and reduce the management of economic costs.

\section{Overview of Wisdom Campus System Based on Android Platform}

The smart campus system based on android platform is a systematic mode of intelligent management of schools. It is to make full use of mobile Internet technology, network communication technology, data storage technology, cloud computing, data analysis and other technologies to build a school teachers and students and the campus A network of various types of resources to communicate with each other, and a platform for sharing the state of teachers and students with campus resources. It is an intelligent, efficient, timely, and flexible tool for campus management. It is based on the android platform, designed to open and innovative service platform to create a teaching and management integration, learning and living together, systems and wisdom of the new school management model. It contains the collection of teaching, research, campus life and management and other information collection, intelligent analysis 
and processing, school administrators and each role by function, to provide intelligent data analysis, systematic application services, efficient Campus management. It contains such aspects as "Wisdom Environment, Wisdom Learning, Wisdom Service, Wisdom Management" and more, but "smart" and "smart", "convenient" and "quick" should be emphasized here.

\section{Design Principles}

Intelligent campus platform is a complex structure, involving a wide range of long-term construction of information systems engineering, to enable the construction of smart campus platform healthy and orderly, the overall planning of smart campus to follow the following principles:

Overall Planning, Distribution and Implementation. The smart campus needs to be built in stages. To ensure the campus is advanced and demonstrative, the program aims at the development needs of the campus in the next 3-5 years, proactively plans the campus wisely and avoids the "backwardness of construction" and "Push it again, all updates" waste of resources. Selected hardware and software facilities are the cutting-edge technology solutions in the current field. At the same time, the smart campus to sort out the tasks in phases, to develop phased goals and programs.

Demand-driven, Integration and Innovation. The program to meet the actual needs of education as the basic premise, focusing on teaching and management of the core needs of the development, based on the development of advanced information technology and innovative educational philosophy of innovative design.

Progressive Upgrade and Gradually Improve. Based on the 3- to 5-year plan of smart campus, formulate a reasonable implementation schedule and task decomposition book, steadily push forward the project construction, and gradually upgrade, while construction, application, evaluation, and gradually advance, give full play to the advantages of information technology applications, Make sure the expected construction goal is achieved.

Up and Down Unicom, Open Expansion. The state has already planned and implemented a series of major educational information projects, including the three links and two platforms, the school links, classes and classes, etc. The provincial and municipal districts and counties are also gradually deploying district-based education cloud service platform and smart campus platform Stay in the district cloud platform interface and improve the compatibility of the county platform business. At the same time, smart campus platform needs access to various intelligent hardware, considering the differences of hardware devices, the platform should have good openness.

\section{Design and Implementation of Wisdom Campus System Based on Android Platform}

Mobile Terminal Development Technical Analysis. The construction of mobile smart campus inseparable from the smart phone platform, relying on the android technology platform designed to develop a smart campus system. Development environment for the android mobile platform, the development needs to use the key technologies include android SDK technology, JavaBean technology, ORM lite framework, database development, and so on.

The Overall Structure of Smart Campus System and Detailed Design. Intelligent campus system is divided into four parts: intelligent teaching management system, intelligent logistics management system, intelligent information push system, communication platform. Designed three different roles for students, teachers and administrators and developed three different platforms.

Intelligent teaching management system design is the more important part of the entire system. Intelligent teaching management system through the attendance of teaching attendance, student management, intelligent transfer class, intelligent office to achieve the wisdom of the management of the campus. Intelligent teaching management system which uses the characteristics of students have a campus card, credit card to achieve the attendance of teachers and students to collect and use of Internet technology to send data to the system center. The intelligent tuition sub-system provides an adjustable time classroom arrangement by querying the curriculum and classifying students, teachers in vacant classes, and vacant classroom queries for intelligent analysis. Teachers can use the system to feedback 
the teacher to find the final lesson scheduling information, and submit an application to the administrator. After the administrator confirms, the system will automatically revise the week's schedule and send the schedule information to the students in the tuition class. Through intelligent analysis, the data processing, making it easier for teachers to transfer lessons, inform students more timely and convenient.

The Intelligent Logistics System. The Intelligent Logistics System is a tool for managing school resource equipment. Campus resources are abundant, but because of the students' understanding of school resources, the idle status of some facilities can not be understood even though the utilization of school resources is relatively inefficient. As more school facilities, management is more difficult, equipment failure, can not even deal with, making school resources can not be fully utilized effectively. Intelligent logistics system, through real-time query curriculum database, in a timely manner to find a spare classroom, so that students can find a timely study room can learn. When the school facilities are damaged, the student end of the teacher can push the status of a key device, the relevant maintenance staff can be their online guidance or over repair.

Intelligent Information Push System. The Intelligent Logistics System is a tool for managing school resource equipment. Campus resources are abundant, but because of the students' understanding of school resources, the idle status of some facilities can not be understood even though the utilization of school resources is relatively inefficient. As more school facilities, management is more difficult, equipment failure, can not even deal with, making school resources can not be fully utilized effectively. Intelligent logistics system, through real-time query curriculum database, in a timely manner to find a spare classroom, so that students can find a timely study room can learn. When the school facilities are damaged, the student end of the teacher can push the status of a key device, the relevant maintenance staff can be their online guidance or over repair.

Intelligent Information Push System. Intelligent information push system provides teachers and students of the $\mathrm{s}$ kinds of information query and the system to remind teachers and students. In traditional school management, the message is conveyed through the school to the teacher, the teacher to the monitor again, the monitor again to convey to each dormitory, a tedious level. To convey the effect is not very good, easily missed members. Teachers also need to monitor class one by one notice, often people do not know delay and transfer. The information push system in the smart campus system can make the notification send to each client quickly, and the transfer information can be pushed even if the students fail to attend the class due to class transfer. Information push system also has library loan expiry reminder, results query, job completion reminder and other functions.

Unified Application Access. Third-party application access to provide a standard interface to achieve third-party seamless access, data synchronization and so on. For better data compatibility, the data of each application system will be interacted and called through the platform API interface, and all the interfaces of the platform will be presented in the way of REST design and development. Through uniform application interface management, applications can follow the platform data exchange standard to provide data calling interfaces to other applications on any platform to facilitate data exchange.

Unified Data Standards. Platform design must pay attention to ensure its future scalability, therefore, pay attention to follow the standards of platform design standards, is committed to building education standard cloud platform. Standard construction needs to be the best compatibility, scalability: The most widely used and most widely validated standards are used to enable diverse resources and applications to be used concurrently with this platform; Focus on cross-platform and compatibility features when designing and implementing; Once the resources and applications are reformed in strict accordance with the rules, they are equivalent to entering from diversified and heterogeneous states to peace.

\section{Summary}

Mobile smart campus system based on android platform provides us with ubiquitous learning space, integration of innovative network research, transparent and efficient school management, rich and colorful campus culture, convenient and thoughtful campus life. The development of smart campus system caters to the needs of teachers and students in colleges and universities that popularize the use of 
intelligence. It solves many shortcomings of the traditional campus management model and opens a new era of efficient smart campus management system.

\section{Acknowledgements}

This work was supported by The Ministry of Education cooperation in education and training project (No. 201701020103) .

\section{References}

[1] Chen Wen, Design and implementation of campus information service system based on Android platform. Jinan University, 2012.

[2] Ren Bin. From Digital Campus to Smart Campus. Fujian Computer, 28 (2014): 57-58.

[3] Huang Ronghuai, Zhang Jinbao, Hu Yongbin, and other intelligent campus digital campus development trend. Open Education Research, 18 (2015): 12-27

[4] Honglan Zhang, Joe one by school based on Android and JAVA EE campus information exchange system, Jilin University, 2012.

[5] Yang Chao, Design and Implementation of Electronic Reading Client Based on Android Platform Beijing Jiaotong University, 2012.

[6] Zhang Peiyou, Research and implementation of geometric proof system based on mobile Internet. University of Electronic Science and Technology of China, 2012. 